\title{
AS DESIGUALDADES DE GÊNERO ENFRENTADAS POR MULHERES NO MERCADO DE TRABALHO
}

\author{
Autores ${ }^{1}$ \\ Hanna Barona Silva Mendes ${ }^{2}$ \\ Vitória Santos Oliveira ${ }^{3}$ \\ Tailma Leite Barreto 4 \\ Wivirson Flávio Pereira Dultra ${ }^{5}$
}

\section{RESUMO}

Este artigo busca investigar a manifestação das desigualdades de gênero enfrentadas por mulheres no ingresso e permanência em condições de equidade no mercado de trabalho. A questão decorre de amplas discussões sobre o referido tema que se concentra tão somente nos avanços das conquistas femininas nas últimas décadas, sem se ater a perpetuação e a materialização dessas desigualdades na contemporaneidade. O caminho metodológico do trabalho concentra-se em pesquisa exploratória bibliográfica, tomando como referência análise de indicadores nacionais.

PALAVRAS CHAVES: Desigualdade de gênero; Mulheres; Mercado de trabalho;

\section{RESUMEN}

Este artículo busca investigar la manifestación de la desigualdad de género que enfrentan las mujeres al ingresar y permanecer en condiciones de equidad en el mercado laboral. El problema surge de extensas discusiones sobre el tema antes mencionado, que se centra solo en los avances en los logros de las mujeres en las últimas décadas, sin detenerse en la perpetuación y la materialización de estas desigualdades en los tiempos contemporáneos. La ruta metodológica del trabajo se centra en la investigación bibliográfica exploratoria, tomando como referencia el análisis de indicadores nacionales, noticias y análisis documental.

PALABRAS CLAVE: Desigualdad de género; Mujeres; Mercado de trabajo;

\footnotetext{
${ }^{1}$ Trabalho elaborado para a disciplina Direito do Trabalho I, pelos graduandos do curso de bacharel em Direito na Universidade do Estado da Bahia (UNEB), Campus XIII, sob a orientação do professor Dr. José Araújo Avelino (Email:dravelino@hotmail.com)

${ }^{2}$ Hanna Barona Silva Mendes - E-mail: hannabarona@hotmail.com

${ }^{3}$ Vitória Santos Oliveira - E-mail: vivi_bellas@hotmail.com

${ }^{4}$ Tailma Leite Barreto - E-mail:tailma.barreto@gmail.com.

${ }^{5}$ Wivirson Flávio Pereira Dultra- E-mail: wivirsonflaviopd@gmail.com
} 


\section{INTRODUÇẼ̃O}

O presente estudo tem o intuito de contribuir com as discussões sobre as desigualdades de gênero enfrentadas por mulheres nas relações laborais, tema que tem ganhado visibilidade no âmbito do Direito do Trabalho. Estudos anteriores apontam para um crescente aumento da presença feminina no mercado de trabalho brasileiro. No entanto, estes mesmos estudos evidenciam a situação de extrema desigualdade enfrentada por essas mulheres no cerne destas relações.

Essa dualidade acerca da presença feminina no mercado de trabalho é consequência dos resquícios ainda muito presentes da forma como o trabalho foi organizado historicamente dentro das sociedades. Fortemente marcado pela divisão sexual, essa forma de organização laboral concentra atividades diferentes entre homens e mulheres, atribuindo aos primeiros, atividades consideradas como de "prestígio" social (ligadas a indústrias, comércio, política), enquanto as mulheres são reservadas ocupações sem remuneração, geralmente voltadas para o consumo próprio do núcleo familiar (trabalho doméstico).

Neste sentido, diante de tal panorama, busca-se traçar discussões sobre essas desigualdades enfrentadas pelas mulheres, considerando não só aspectos desse tratamento desigual atribuídos ao fator sexo no sentido bio-fisológico, mas relacionados à questão de gênero, ou seja, as relações sociais desiguais de poder entre homens e mulheres no mercado de trabalho. Assim, busca-se questionar acerca da manifestação material da desigualdade de gênero. Afinal, quais são as principais dificuldades oriundas da questão de gênero, enfrentadas por mulheres no ingresso e permanência em condições de equidade no mercado de trabalho?

Dessa forma, buscando a construção de um referencial teórico com bases sólidas sobre o tema, debruça-se sobre pesquisa bibliográfica e documental. Assim, a fim de desenvolver as questões fundantes, dedica-se ainda a análise legislativa concernente ao tema.

Neste sentido, o caminho metodológico se desdobra em pesquisa exploratória e análise de indicadores nacionais.

\section{DO GÊNERO À EPISTEMOLOGIA FEMINISTA: AS MULHERES COIMO NOVOS SUJEITOS POLÍtTICOS}


A palavra gênero possui vários significados que podem ser definidos através da linguagem. No entanto, durante o percurso do texto, pretende-se explicar o significado do gênero sob a ótica feminista. A princípio, o gênero pode ser entendido como a diferença entre homens e mulheres no processo de hierarquização social. Todavia, a tentativa de explicar as diferenças entre homens e mulheres necessitou ao longo do tempo a construção de uma categoria social - "gênero", então, é preciso salientar que esta categoria não é unânime, sendo assim, todos e todas que estudam e trabalham a problemática do gênero, elaborou diversos conceitos, tais como a identidade de gênero ou de mulheres de formas específicas (negras, trans, indígenas).

Entretanto, Joan Scott (1995) conceituou de uma forma elaborada o termo '"gênero'”. Segundo Scoot (1995):

Gênero é um elemento constitutivo das relações sociais fundadas sobre as diferenças percebidas entre os sexos e também um modo primordial de dar significado às relações de poder. (SCOOT, p. 86, 1995)

A partir desse conceito é possível traçar uma discussão no que tange a diferença entre sexo e gênero, pois, "segundo uma famosa frase de uma escritora francesa Simone de Beauvoir, não se nasce mulher, torna-se mulher. As identidades de sexo são construídas socialmente e podem ser modificadas". (SABADELL, p. 279, 2010).

Segundo Sabadell (2010):

As feministas propusseram empregar o termo "gênero"' (em inglês: gender) ao invés do termo "sexo"' (em inglês) para indicar as diferenças entre os sexos que vão além das biológicas. Isto permite falar de homens e mulheres fora do determinismo biológico. Trata-se de um aspecto importante, porque grande parte das diferenças entre os sexos não são devidas a diferenças biológicas, mas decorrem de uma construção social da realidade. Em palavras simples, quebra-se o discurso de caráter naturalista que apresenta as diferenças entre homens e mulheres como eternas." (SABADELL, p. 279, 2010).

O gênero expressa as relações de poder das quais serão originadas as diferenças fundamentais em termos de trabalhos, atribuições na família, diferenças nos cargos públicos, etc. Essas relações de poder é o que explica a forma na qual as pessoas constituem a expressão do gênero na sociedade, pois através do processo de informação que cada indivíduo recebe ao decorrer de sua formação social pode moldar as formas que o mesmo irá realizar as diferentes atividades no convívio social. Com isso, as mulheres são educadas para um cuidado interno, sendo assim, é através do lar (a esfera privada) que as relações de poder foram moldadas e construídas socialmente para o gênero feminino, já os homens são educados para um cuidado externo (a esfera pública), pois estes estão no comando das relações 
que envolvem o convívio social. Embora crescente o número de mulheres que vem adentrando os espaços públicos, as pesquisas que envolvem a discussão de gênero ainda mostram a sua pouca representatividade nesses espaços. Sendo assim, essa é uma necessidade de discussão, com enfoque ao que tange uma análise juslaboral, que será traçado nos próximos tópicos do texto.

Ademais, é preciso informar que esse trabalho se propõe a entender a relação - mercado de trabalho e gênero através da ótica epistemológica feminista. $O$ feminismo que é reconhecido majoritariamente como um conjunto de movimentos políticos e sociais que possui como pauta - as reivindicações das mulheres, tais como - a liberdade e a autonomia do corpo. Entretanto, o feminismo também é um movimento epistemológico que estuda as lacunas existentes nas mais diversas áreas do conhecimento e os aspectos fundamentais no que diz respeito às mulheres. Pensar de uma forma epistemológica feminista é se aprofundar na compreensão das mulheres e de todo o sistema social que está a sua volta. A produção do conhecimento feminista é realizado através de história reais das mulheres, experiências concretas de suas vivências, a sua participação dentro da academia na produção do conhecimento, mas também, como atrizes adentrando nos espaços etc.

O movimento feminista não é homogêneo, pois este possui diversas pautas e especificidades, como demonstra Sueli Carneiro (2005):

\begin{abstract}
Ao politizar as desigualdades de gênero, o feminismo transforma as mulheres em novos sujeitos políticos. Essa condição faz com que esses sujeitos assumam, a partir do lugar em que estão inseridos, diversos olhares que desencadeiam processos particulares subjacentes na luta de cada grupo particular. Ou seja, grupos de mulheres indígenas e grupos de mulheres negras, por exemplo, possuem demandas específicas que, essencialmente, não podem ser tratadas, exclusivamente, sob a rubrica da questão de gênero, se esta não levar em conta as especificidades que definem o ser mulher neste e naquele caso. Essas lógicas particulares vêm exigindo, paulatinamente, práticas igualmente diversas que ampliem a concepção e o protagonismo feminista na sociedade brasileira, salvaguardando as especificidades. (CARNEIRO, p. 209, 2005)
\end{abstract}

As epistemologias feminista pós-moderna vez introduzir uma crítica ao feminismo tradicional, pois este através do processo de generalização inviabiliza o debate sobre gênero atrelado a questões de sexualidade, raça, classe e as consequências do imperialismo. Ademais, para que se possa alcançar essa discussão é necessário que se faça uma leitura descolonial do feminismo e atravessar horizontes para entender toda essa problemática, pois assim, o feminismo pode superar a compreensão 
hegemônica europeia do movimento, devido esse ser incompatível para o processo de construção da equidade de gênero.

Sendo assim, é preciso que se compreendam as múltiplas variedades de mulheres - latinas, africanas, asiáticas etc; mas também, as estruturas de poder que vão desde a estratificação interna à enorme variedade cultural, as suas experiências históricas e sociais, as realidades econômicas diversas e toda a conjuntura social que as envolvem. E nesse processo permitir que estas possam produzir as suas epistemologias.

\section{A PRESENÇA DAS MULHERES NO IMERCADO DE TRABALHO: PRINCIPAIS DESAFIOS}

A ocupação das mulheres aos espaços no mercado de trabalho esteve historicamente condicionada a organização social do trabalho, marcado por uma divisão sexual, na qual homens e mulheres foram colocados em posições hierarquicamente distintas, atribuindo sempre as mulheres funções consideradas "inferiores", sem remuneração, voltadas ao cuidado do "lar".

A socióloga Danièle Kergoat, ao abordar divisão do trabalho e as relações sociais de sexo, traz uma importante visão sobre essa forma de organização social:

A divisão sexual do trabalho é a forma de divisão do trabalho social decorrente das relações sociais de sexo; essa forma é adaptada historicamente e a cada sociedade. Ela tem por características a destinação prioritária dos homens à esfera produtiva e das mulheres à esfera reprodutiva e, simultaneamente, a apreensão pelos homens das funções de forte valor social agregado (políticas, religiosas, militares etc). (KERGOAT, p.56, 2003)

Ainda segundo Kergoat (2003), essa organização social do trabalho é erguida sobre dois princípios, o primeiro é concernente a separação, ou seja, existem trabalhos de homens, e trabalho de mulheres, já o segundo, diz respeito à hierarquização, o trabalho de homem "vale" mais do que o trabalho de uma mulher.

Dessa forma, nota-se uma distinção construída em decorrência das relações hierárquicas de gênero, que excluem a mulher da esfera pública, e se configuram como formas de violência e opressão feminina, furtos de uma sociedade de dominação masculina, de uma sociedade patriarcal. 
Neste sentido, nota-se que a divisão sexual do trabalho tem sido um dos fatores que impulsionam a manifestação material da desigualdade gênero, enfrentadas por mulheres no ingresso ao mercado de trabalho.

Segundo o estudo do IBGE (2018) sobre Estatísticas de Gênero: Indicadores Sociais das Mulheres no Brasil, divulgado em março de 2018 (como base em levantamento realizado em 2016), as mulheres brasileiras dedicam-se às tarefas domésticas cerca de $70 \%$ a mais de horas do que os homens.

Desta forma, em decorrência da dedicação a afazeres domésticos, muitas mulheres acabam impossibilitadas de ingressar em cargos de trabalho no âmbito público, e quando ingressam, se deparam com a necessidade de conciliar trabalho remunerado e as tarefas do "lar", assim, terminam ocupando cargos com carga horária reduzida em relação aos ocupados por homens, o que tem afetado diretamente o crescimento econômico/financeiro feminino.

Outro fator agravante que contribui com desigualdade de gênero no mercado de trabalho, está diretamente ligada a discriminação salarial sofrida por mulheres em suas ocupações, que acabam recebendo remunerações menores pelo desempenho das mesmas tarefas profissionais que os homens. Essa discriminação salarial evidenciada é expressamente proibida constitucionalmente, uma vez que a Carta Magna estabelece que todos são iguais perante a lei, essa vedação fica expressa no art. $7^{\circ}, \mathrm{XXX}$, que proíbe dentre outras coisas a distinção de salários em função de sexo.

A questão da igualdade entre homens e mulheres no trabalho deve ser tratada como uma questão de direitos humanos e como um requisito indispensável ao regime democrático.

A previsão constitucional da igualdade entre homens e mulheres se aplica a diversos aspectos da relação de emprego, como, por exemplo, em relação à capacidade para trabalhar e celebrar contrato de trabalho, ao cumprimento de jornada de trabalho igual e ao recebimento do mesmo salário para trabalho de igual valor. (ROMAR, p. 778, 2018)

No entanto, em inúmeros casos, a discriminação salarial tem persistido. Esse fator tem justificado a luta de milhares de trabalhadoras contra a desigualdade salarial.

Ainda segundo o estudo do IBGE, essa diferença de remuneração é ainda maior entre cargos de nível superior completo, o referido estudo aponta que as mulheres receberam $63,4 \%$ a menos que os homens em 2016. 


\section{XLABORJUR|5

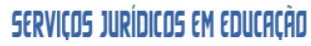

Segundo Resende (2016), na prática, a lei não consegue reprimir as formas de discriminação, pela carga de subjetividade carregada nos critérios de seleção, promoção, dentre outros, o que gera consequentemente uma dificuldade de comprovação. "O que a lei consegue inibir é apenas a discriminação aberta, escancarada." (RESENDE, p. 1070, 2016)

Dentre o rol de dificuldades, mais evidentes, enfrentadas pelas mulheres, em função de gênero, no ambiente de trabalho, destaca-se também o assédio. Estudos apontam que as mulheres são vítimas preferenciais de assédio no ambiente de trabalho, configurando-se, assim, como desafio para estabilização e até mesmo para ascensão feminina em suas carreiras profissionais.

O assédio no ambiente de trabalho é uma das formas mais ultrajantes que constrangem o trabalhador, acontecendo na maioria dos casos silenciosamente e sem a presença de testemunhas, e afetando moralmente e psicologicamente suas vítimas, estas em seu maior porcentual as mulheres. (PASCOAL, p.02, 2017)

Em importante destacar ainda, que o assédio contra mulheres acontece principalmente de maneira sexual.

Curiosamente, os casos de assédio moral, quando a vítima é uma mulher, rapidamente passam a ser casos de assédio sexual, e quando já iniciam como sexual, se diante de uma forte atitude negativa da vítima, o comportamento do agressor pode restar como assédio moral. Infelizmente, em qualquer dos cenários, a mulher ainda se encontra numa situação de desestabilização, vulnerabilidade e culpa. Sentindo-se muitas vezes sem saída e com medo de ser marcada no seu meio profissional, acaba "desistindo" do emprego. (SIMÕES; MELLO, p.13, 2016)

O Ministério Público do Trabalho (MPT), com apoio da Organização Internacional do Trabalho (OIT), elaborou em 2017, uma cartilha buscando esclarecer as principais dúvidas sobre assédio sexual no ambiente de trabalho, denominada "Assédio Sexual no Trabalho: perguntas e respostas", o referido documento define essa forma de discriminação como:

Assédio sexual no ambiente de trabalho é a conduta de natureza sexual, manifestada fisicamente, por palavras, gestos ou outros meios, propostas ou impostas a pessoas contra sua vontade, causando-lhe constrangimento e violando a sua liberdade sexual. (BRASIL, p. 09, 2017) 
Assédio sexual é crime, e está previsto no art. 216 do Código Penal brasileiro. A violação do referido dispositivo legal, viola os Direitos Humanos segundo a cartilha do Ministério Público do Trabalho - MPT (2017):

O assédio sexual viola a dignidade da pessoa humana e os direitos fundamentais da vítima, tais como a liberdade, a intimidade, a vida privada, a honra, a igualdade de tratamento, o valor social do trabalho e o direito ao meio ambiente de trabalho sadio e seguro. (BRASIL, p.09, 2017)

Os assédios sofridos por mulheres trazem danos psicológicos, físicos, emocionais, provocando-as a ideia de inferioridade, inconveniência e constrangimento, do qual afasta o profissionalismo e respeito que se deve prevalecer no ambiente de trabalho. Muitas vezes isso acontece, pela objetificação que se faz sobre a mulher e seu corpo, e não sobre a associação dela como um ser pensante e capaz.

\section{CONSIDERAÇÕES FINAIS}

A pesquisa realizada teve como objetivo investigar a perpetuação da desigualdade de gênero no mercado de trabalho brasileiro. Assim, buscando evidenciar as principais dificuldades enfrentadas por mulheres no ingresso e permanência em condições de equidade no mercado de trabalho.

A metodologia adotada, buscou através de pesquisa exploratória bibliográfica análise de indicadores nacionais, notícias e análise documental, compreender os fatores que dificultam a inserção e a permanência feminina no mercado laboral.

No quesito inserção no mercado, os resquícios da divisão sexual do trabalho ainda muito presentes na sociedade brasileira, tem gerado inúmeras dificuldades as mulheres que precisam se desdobrar em jornadas duplas entre os afazeres domésticos e trabalho formal.

A dedicação às tarefas domésticas tem feito com que mulheres optem por ocupações com carga horária menor e consequentemente com menores remunerações.

No entanto, a discriminação salarial está presente mesmo no desempenho das mesmas funções, com carga horária compatíveis. Sendo esta disparidade ainda maior entre cargos de nível superior.

Neste sentido, o estudo em questão evidencia a persistência das desigualdades entre homens e mulheres no mercado de trabalho brasileiro, causando inúmeras dificuldades de acesso às oportunidades e direitos. 


\section{REFERÊNCIAS:}

BRASIL. Constituição da República Federativa do Brasil.1988. Disponível em: <https://www.planalto.gov.br/ccivil_03/constituicao/constituicao.htm> Acesso em: 05 de jan. de 2020.

BRASIL. Assédio Sexual no Trabalho: Perguntas e respostas. 2017. Disponível em: PERGUNTAS E RESPOSTAS Acesso em: 06 de jan. de 2020.

CARNEIRO, Suely. O papel do movimento feminista na luta anti-racista. In: História do negro no Brasil: o negro na sociedade brasileira. Fundação Cultural Palmares, CNPQ, 2004, p. 286-336.

IBGE. Coordenação de População e Indicadores Sociais. Estatísticas de Gênero: Indicadores Sociais das Mulheres no Brasil. Rio de Janeiro, 2018. Disponível em: <Estatísticas de Gênero>. Acesso: 20 de jan. de 2020.

PASCOAL, Flávia Xênia Souza. Assédio moral e assédio sexual no ambiente de trabalho, 2017. Disponível em: <Assédio moral e assédio sexual no ambiente de trabalho> Acesso em: 06 de jan. de 2020.

RESENDE, Ricardo. Direito do trabalho esquematizado. 6. ed. rev., atual. e ampl. - Rio de Janeiro: Forense; São Paulo: MÉTODO, 2016.

ROMAR, Carla Teresa Martins. Direito do trabalho / coordenador Pedro Lenza. - 5. ed.- São Paulo : Saraiva Educação, 2018.

SABADELL, Ana Lucia. Manual de Sociologia Jurídica.: introdução a uma leitura externa do direito. 5. Ed. Rev. E atual. - São Paulo: Editora Revista do Tribunais, 2010.

SÃO PAULO. Prefeitura Municipal Coordenadoria Especial da Mulher Trabalho e cidadania ativa para as mulheres: Desafios para as Políticas Públicas. São Paulo: Coordenadoria Especial da Mulher, 2003.

SCOTT, Joan Wallach. Gênero: uma categoria útil de análise histórica. Educação \& Realidade. Porto Alegre, vol. 20, n² 2, jul./dez. 1995, pp. 71-99.

SIMÕES, Ana Paula; MELLO, Kauana Andriele. A DISCRIMINAÇÃO DE GÊNERO NO AMBIENTE DE TRABALHO: PARTICULARIDADES E EFEITOS DO ASSÉDIO MORAL CONTRA AS MULHERES. Disponível em: <https://online.unisc.br/acadnet/anais/index.php/sidspp/article/view/15877> Acesso em: 06 de fev. de 2020. 